\title{
MINIMIZATION PRINCIPLE IN ORDERED BANACH SPACES AND APPLICATION VIA EKELAND'S VARIATIONAL PRINCIPLE
}

\author{
Amina Boucenna, Mabrouk Briki, Toufik Moussaoui \\ AND DONAL O'REGAN
}

Abstract. In this paper we establish a minimization principle in an ordered Banach space (in particular in a Riesz-Banach space). As an application we discuss the existence of a positive solution for a boundary value problem on the half-line even when the nonlinear term is signchanging.

Mathematics subject classification (2010): 35B38, 47L07.

Keywords and phrases: Critical point, Ekeland's variational principal, cone, Riesz-Banach space, minimization principle.

\section{REFERENCES}

[1] K. Ait-Mahiout, S. Djebali And T. Moussaoui, Multiple solutions for an impulsive boundary value problem on the half line via Morse theory, to appear in Topological Methods in Nonlinear Analysis, DOI: 10.12775/TMNA.2016.003.

[2] C. D. Aliprantis and O. Burkinshaw, Positive operators, Academic Press, New York, 1985.

[3] M. BRiki, S. DJebali And T. Moussaoui, Solvability of an impulsive boundary value problems on the half-line via critical point theory, accepted in Bullet. Iranian Math. Soc.

[4] R. KAJIKIYA, Mountain pass theorem in ordered Banach spaces and its applications to semilinear elliptic equations, Nonlinear. Differ. Appl. 19 (2012), 159-175.

[5] O. Kavian, Introduction à la Théorie des Points Critiques et Applications aux Problèmes Elliptiques, Springer-Verlag, 1993.

[6] W. A. J. Luxemburg And A. C. ZaAnen, Riesz Spaces, vol. 1. North-Holland, London, 1971. 